\title{
Erratum: "Informative Value of Changes in Hand Skin Temperature in Response to Hypoxic Exposure" [Hum. Phys. 31 (3), 340 (2005)]
}

\author{
A. L. Maksimov \\ Arktika International Research Center, Far East Division, Russian Academy of Sciences, Magadan, Russia \\ e-mail: arktika@online.magadan.su
}

In the article "Informative Value of Changes in Hand Skin Temperature in Response to Hypoxic Exposure" by A.L. Maksimov Human Physiology (2005, vol. 31, no. 3, p. 340) in the left column, line 8 from the bottom the text in brackets should read (Table 3, Ia and Ib) and in line 6 the text in brackets should read (Table 3, IIa and IIb). 